\title{
A Study of Psychiatric Morbidity in Newly Detected HIV Positive Individuals
}

\author{
Bhirud Mahesh G. ${ }^{1}$, Meshram Shrikant S. ${ }^{2}$, Gupte Sunil G. ${ }^{3}$ \\ ${ }^{1}$ Associate professor, Department of Psychiatry, \\ ${ }^{2}$ Assistant Professor, Department of Psychiatry, Shri V.N.G.M.C. Yavatmal. \\ ${ }^{3}$ Professor, Department of Psychiatry \\ ${ }^{1,3}$ Vasantrao Pawar Medical College and Research Center, Nashik, Maharashtra, India \\ Email-drmgbhirud@gmail.com \\ Corresponding author - Dr. Mahesh Bhirud
}

\begin{abstract}
Introduction: Several researches on HIV and other STDs often focused on vulnerable people like injection drug users, and commercial sex workers. A less but well-recognized risk group are men and women living with mental illnesses, such as substance abuse, schizophrenia, bipolar disorder, and other mood disorders. Methodology: Adults $(\mathrm{N}=107)$ newly detected as having infection of HIV were screened for the information regarding socio-demographic and psychiatric correlates. The patients were interviewed using Mini-international Neuropsychiatry interview English Version 6.0.0, and diagnosis was confirmed using a brief structured interview for the major Axis I psychiatric disorders in DSM-IV and ICD-10.

Results: Among the $107 \mathrm{HIV}$ infected individuals, 54 (50.47\%) people were diagnosed to be suffering from axis I psychiatric disorder, substance abuse being the most common, followed by mood disorders, anxiety disorder and schizophrenia. Multiple sex partners, non-use of barrier method during sexual activity and, sex with commercial sex workers were associated risk factors with the psychiatric disorders in patients newly diagnosed with HIV infection.

Conclusion: Psychiatric patients are a high risk group for HIV infection and must be screened regularly for the same.
\end{abstract}

Key Words: HIV, substance abuse, risk factors, psychiatric patients.

(Paper received $-24^{\text {th }}$ April 2017, Peer review completed $-29^{\text {th }}$ May, Accepted $-30^{\text {th }}$ May 2017)

\section{INTRODUCTION}

HIV infection is a global pandemic. It is expanding at an alarming rate. India has third largest number of population living with HIV/AIDS. We are aware of the fact that HIV infected patients develop psychiatric symptoms during the course of their illness, mentally ill people are, on the other hand, vulnerable to HIV infection. Various studies show sero-prevalence rates variably ranging from $2 \%$ to $29 \%$, much higher than those for the general population [1-3].

This means HIV infection and psychiatric illnesses are related in a bidirectional way which has received a considerable attention in the last decade owing to the emotional impact of the disease and its effect on an individual's personal, sexual, occupational and social life. Investigation of the prevalence, patterns, and correlates of HIV-related risk behaviours in the Indian context is needed to guide the development of behavioural risk reduction and prevention programs. Purpose of the study was to investigate the prevalence and correlates of risk behaviour for psychiatric disorders in newly detected HIV positive individuals. By identifying these risk characteristic, it may be possible to develop better educational and prevention approaches for this population. 
Table1- Various studies showing the prevalence of HIV infection in patients suffering from psychiatric disorders

\begin{tabular}{|c|c|}
\hline Study & Sero-prevalence among psychiatry patients (\%) \\
\hline Stefan MD et al [1] and Carey MP et al [2] & 4 to 23 \\
\hline Chandra PS et al [3] & 3.4 \\
\hline Chandra, Ravi et al [3] & 2.1 \\
\hline Chandra, Krishna et al [4] & 3.4 \\
\hline Campos LN et al [5] & developed countries:0 - 29 \\
(24 published studies) & developing countries:0 - 23.8 \\
\hline
\end{tabular}

\section{MATERIALS AND METHODS}

Site: The study was conducted in the Department of Psychiatry, Dr. Vasantrao Pawar Medical College and Hospital, Nasik.

Sample: After getting approval from the ethics committee, a sample of 107 participants newly diagnosed as HIV positive was selected over a period of 18 months. Individuals newly diagnosed as HIV positive, above the age of 18 years and willing to participate were included in the study. All the participants provided written and valid informed consent for the research procedure. Individuals excluded were those under the age of 18 years, with low intellectual capacity, memory disturbances, neurological diseases, past history suggestive of head injury having difficulty in recalling past events and those in the state of substance intoxication and withdrawal.

Newly diagnosed HIV individuals were screened for information regarding risk behaviour as well as demographic and psychiatric correlates. An informed consent was taken from the individuals and relatives. The patients were interviewed using Mini-international Neuropsychiatry interview English Version 6.0.0 [6], a brief structured interview for the major Axis I psychiatric disorders in DSM-IV and ICD-10. Then clinical diagnosis was confirmed on discussing with two qualified psychiatrists in the department of psychiatry.

\section{Statistical Analysis}

Baseline assessments were obtained for eligible patients. Frequency distributions for socio-demographic and categorical variables were obtained. For the statistical analysis, the SPSS Software Package for window version 11.5 was used.

\section{RESULTS}

Among the $107 \mathrm{HIV}$ infected individuals, 54 (50.47\%) people were diagnosed tobe suffering from axis I psychiatric disorder. Substance abuse was the most common disorder, 44 (41.12\%) had substance abuse of which $19(17.76 \%)$ were suffering from another co-morbid axis I disorder. Other axis I disorders found were mood disorders ( 9 i.e 8.41 ) and anxiety disorders (1 i.e. $0.93 \%)$.

In the study population, the age of the individuals ranged from minimum of 20 years to maximum of 59 years. Mean age of sample is $33.11(\mathrm{SD}=6.3)$. In our study, majority of the sample belonged to the age group of 30 to 39 years i.e. $62(57.9 \%$ ), thus middle aged individuals formed the study group. It was found that the axis I psychiatric diagnosis was not present significantly high in any particular age group.

The axis I psychiatric diagnosis was present significantly high in males. Among the participants, males were predominant i.e. 68 (63.55 \%) and females were 39 (i.e. $36.45 \%$ ). In males substance abuse i.e. 25 $(23.36 \%)$ was most common, while mood disorder was more common i.e. 7 (6.54 \%) in females. A study by Chandra and others [4] reported that high risk behaviour is more common in women with bipolar affective disorder during the actively psychotic or manic phase, when poor judgment, poor negotiation 
skills and lack of control over sexuality may land them in high risk behaviours and severe coercive experiences. Another study by Chandra and others reported that mentally ill females with sexual coercion had higher prevalence of HIV related risk behaviour over lifetime [7].

Table 2- Axis I psychiatric disorders found in the study group

\begin{tabular}{|c|l|c|}
\hline Sr. No & \multicolumn{1}{|c|}{$\begin{array}{c}\text { Axis I Psychiatric diagnosis } \\
\text { (ICD-10) }\end{array}$} & Total \\
\hline A. & Alcohol abuse & 17 \\
\hline B. & Alcohol \& cannabis abuse & 8 \\
\hline C. & Total SA (A+B) & 25 \\
\hline D. & SA + Schizophrenia & 1 \\
\hline E. & SA + Mood disorder & 14 \\
\hline F. & SA + Anxiety d/o & 4 \\
\hline G. & Total (D+E+F) & 19 \\
\hline H. & Mood disorder & 9 \\
\hline I. & Anxiety d/o & 1 \\
\hline J. & Total person with Axis I (C+G+H+I) & 54 \\
\hline K. & Person without Axis I diagnosis & 53 \\
\hline L. & Total (J+K) & 107 \\
\hline
\end{tabular}

(SA- Substance abuse)

Individuals with unskilled occupation formed the majority of the sample i.e.54 (51.40\%) followed by housewives 28 (i.e. $25.23 \%$ ) and individuals with skilled occupations 25 (i.e.23.36 \%). In individuals with unskilled occupations, 34 (i.e. 31.77\%) were having at least one psychiatric diagnosis, substance abuse i.e. $19(17.75 \%)$ being the most common. In skilled individuals, substance abuse comorbid with axis I psychiatric diagnosis was most common i.e. 7 (6.54 \%) followed by substance abuse i.e.(5.60 \%). Out of total substance abuse, 19 (i.e. 17.75\%) belonged to the unskilled group. Among them 14 (i.e.13.8\%) were alcohol abuse and 5 (i.e.4.67\%) were both alcohol and cannabis abuse. It was found that the axis I psychiatric diagnosis was present significantly high in unskilled individuals.

The study subjects in present study denied any history of homosexual activity. Majority of the study population was married i.e. 82(76.63 \%) followed by unmarried 16(i.e.14.95\%) and separated/ divorced / widow / widower 9 (8.41\%). Among the married people substance abuse was most common i.e.17 (15.88 $\%$ ), among unmarried individuals substance abuse and substance abuse comorbid with axis I psychiatric morbidity was found to be equal i.e. 5 (4.67 \%) and among separated / divorced / widow / widower, mood disorder was most common axis I psychiatric diagnosis i.e. 4 (3.13 \%). It was found that the axis I psychiatric diagnosis was present significantly high in married individuals.

Among the total of 107 participants, 84 (i.e. $78.50 \%$ ) exhibited awareness about HIV and the various routes of the spread of HIV, while 23 (i.e.21.49 \%) individuals were unaware about it. Among those, aware of HIV and various routes of spread of HIV, 49 (i.e. $45.9 \%$ ) had at least one axis I psychiatric diagnosis, substance abuse being the most common i.e. 23(21.49\%), followed by substance abuse comorbid with another axis I psychiatric disorder i.e.16 (14.95\%) and mood disorder i.e. $9(8.91 \%)$.

It was found that 75 (i.e. $70.9 \%$ ) had history of multiple sex partners, while 32(i.e. $29.90 \%$ ) did not. Among those with multiple sex partners 52 (i.e. $48.59 \%$ ) fulfilled criteria for at least one axis I psychiatric diagnosis, again substance abuse being most common i.e.25 (23.36 \%). Among two individuals not having multiple sex partners, one i.e. $0.93 \%$ was diagnosed as anxiety disorder and another as mood disorder.

73 (i.e. $68.22 \%$ ) individuals gave history of using barrier methods sometime during sexual activity, and 34 (i.e. $31.77 \%$ ) never used any barrier method. Those who never used barrier method during sexual activity 24(i.e. 22.42 \%) had at least one axis I psychiatric diagnosis. Guimaraes M.D et al. [8] reported that the overall prevalence of lifetime unprotected sex among psychiatric patients is higher than general population. 
Table 3- Socio-demographic profile

\begin{tabular}{|c|c|c|c|c|c|c|}
\hline \multicolumn{2}{|l|}{ Variables } & \multirow{2}{*}{$\begin{array}{c}\text { Axis I } \\
\text { diagnosis }\end{array}$} & \multirow{2}{*}{$\begin{array}{c}\text { Without } \\
\text { Axis I } \\
\text { diagnosis }\end{array}$} & \multirow{2}{*}{$\begin{array}{r}\text { Total } \\
\\
31\end{array}$} & \multirow{2}{*}{$\begin{array}{c}\begin{array}{c}\text { Chi } \\
\text { square } \\
\text { test }\end{array} \\
\left(\mathbf{X}^{2}\right)\end{array}$} & \multirow{4}{*}{$\begin{array}{l}\text { P value } \\
\\
>0.05 \\
\text { Not } \\
\text { significant }\end{array}$} \\
\hline \multirow[t]{5}{*}{ Age (in years) } & $20-29$ & & & & & \\
\hline & $30-39$ & 33 & 29 & 62 & & \\
\hline & $40-49$ & 7 & 4 & 11 & & \\
\hline & $50-59$ & 3 & 0 & 3 & & \\
\hline & & 54 & 53 & 107 & & \\
\hline \multirow[t]{3}{*}{ Gender } & Male & 46 & 22 & 68 & \multirow[t]{3}{*}{22.02} & \multirow{3}{*}{$\begin{array}{l}<0.05 \\
\text { Significant }\end{array}$} \\
\hline & Female & 8 & 31 & 39 & & \\
\hline & Total & 54 & 53 & 107 & & \\
\hline \multirow[t]{4}{*}{ Occupation } & Skilled & 16 & 9 & 25 & \multirow[t]{4}{*}{19.8} & \multirow{4}{*}{$\begin{array}{l}<0.05 \\
\text { Significant }\end{array}$} \\
\hline & Unskilled & 34 & 21 & 55 & & \\
\hline & Housewife & 4 & 23 & 27 & & \\
\hline & Total & 54 & 53 & 107 & & \\
\hline \multirow[t]{4}{*}{ Marital status } & Married & 34 & 48 & 82 & \multirow[t]{4}{*}{11.40} & \multirow{4}{*}{$\begin{array}{l}<0.05 \\
\text { Significant }\end{array}$} \\
\hline & Unmarried & 13 & 3 & 16 & & \\
\hline & Separated/Widow & 7 & 2 & 9 & & \\
\hline & Total & 54 & 53 & 107 & & \\
\hline
\end{tabular}

In the study population 45 (i.e. $42.05 \%$ ) gave history of sexual activity with commercial sex workers, while 62 (i.e.57.94 \%) denied similar history. Those individuals who gave history of sexual activity with commercial sex workers, 35 (i.e. $32.71 \%$ ) of them had at least one psychiatric diagnosis.

\section{DISCUSSION}

The most important finding in this study is that presence of psychiatric illness can be a strong risk factor for acquiring HIV infection and it can affect the treatment compliance, too, in such patients. Surprisingly axis I psychiatric diagnosis was present significantly high in individuals aware about HIV and various routes of its spread. Possibly individuals with psychiatric disorders have increased contact with health care providers and hence are aware about HIV. This aspect needs further careful evaluation.

Axis I psychiatric diagnosis was present significantly high in the groups of individuals with history of sex with commercial sex workers, in the individuals with multiple sex partners and the individuals who never used any barrier method during sexual activity. All these activities could be the part of impulsivity or inability to delay gratification and diminished judgment and insight in individuals with Axis I psychiatric disorder. Individuals with psychiatric disorders (including personality disorders, substance use disorders, and bipolar disorder) are known for impulsive behavior [9].

Several factors such as sexual abuse, homelessness and impaired judgment regarding sexual relationships, drug abuse make mentally ill patients vulnerable for casual or coercive sexual relationship and put them at high risk for HIV. The common psychiatric disorders found to be a risk for contracting HIV are Schizophrenia, bipolar affective disorder, depression and substance dependence [3]. Multiple sexual contacts is the commonest route of transmission among these patients. Psychiatric patients are more liable to contract HIV when they are under the influence of alcohol, are actively psychotic or have a combination of the two since these factors enhance the chances of a person to engage in risky and unprotected sexual behaviour. Inconsistent use of condoms [10-11] less well informed about sexually transmitted infections [12], poor motivation to adopt risk reduction strategies [13], and lack of interpersonal and social skills needed to negotiate for safer sexual relationships [14], problem solving, planning and judgment deficiency 
[15] are the contributory risk factors among psychiatric patients. Other risk behaviours include sexual partners with risk behaviours (a partner having sexually transmitted disease, IV drug abuse, having multiple sexual partners), multiple sexual partners and exchanging money for sex. Increased sexual activity is likely in schizophrenia, and a recognized feature of mania may increase risk of contracting HIV [15].

Table 4 - Psychiatric morbidity and risk factors for contracting HIV infection

\begin{tabular}{|c|c|c|c|c|c|c|}
\hline \multicolumn{2}{|l|}{ Risk Factors } & \multirow{2}{*}{$\begin{array}{c}\text { Axis I } \\
\text { diagnosis }\end{array}$} & \multirow{2}{*}{$\begin{array}{c}\text { Without } \\
\text { Axis I } \\
\text { diagnosis }\end{array}$} & \multirow{2}{*}{$\begin{array}{c}\text { Total } \\
\\
84 \\
\end{array}$} & \multirow{4}{*}{$\begin{array}{c}\text { Chi } \\
\text { square } \\
\text { test } \\
\left(\mathrm{X}^{2}\right) \\
9.67\end{array}$} & \multirow{4}{*}{$\begin{array}{l}\text { P value } \\
\\
<0.05 \\
\text { Significant }\end{array}$} \\
\hline \multirow[t]{3}{*}{ Awareness about HIV } & Yes & & & & & \\
\hline & No & 5 & 18 & 23 & & \\
\hline & Total & 54 & 53 & 107 & & \\
\hline \multirow[t]{3}{*}{ Multiple sex partners } & Yes & 52 & 23 & 75 & \multirow[t]{3}{*}{35.7} & \multirow{3}{*}{$\begin{array}{l}<0.05 \\
\text { Significant }\end{array}$} \\
\hline & No & 2 & 30 & 32 & & \\
\hline & Total & 54 & 53 & 107 & & \\
\hline \multirow[t]{3}{*}{ Use of barrier method } & Sometimes & 30 & 43 & 73 & \multirow[t]{3}{*}{8.07} & \multirow{3}{*}{$\begin{array}{l}<0.05 \\
\text { Significant }\end{array}$} \\
\hline & No & 24 & 10 & 34 & & \\
\hline & Total & 54 & 53 & 107 & & \\
\hline \multirow[t]{3}{*}{ Sex with CSW } & Yes & 35 & 10 & 45 & \multirow[t]{3}{*}{23.17} & \multirow{3}{*}{$\begin{array}{l}<0.05 \\
\text { Significan }\end{array}$} \\
\hline & No & 19 & 43 & 62 & & \\
\hline & Total & 54 & 53 & 107 & & \\
\hline
\end{tabular}

Severe mental illness may increase risk of HIV infection by contributing to indiscriminate sexual activity or drug use at times of decompensation [16-18]. Prevalent substance abuse and exchanging sex for drugs, money and food put person with severe mental illness at increased risk [19]. In addition to these factors, patients with chronic mental illnesses tend to live in neighbourhoods with very low socioeconomic level, whose inhabitants have a high rate of substance misuse, alcoholism and sexually transmitted diseases, what ultimately predisposing the individuals for HIV infection [20]. Substance use disorder, another psychiatric illness, has a two-fold relationship with HIV risk. Alcohol, opioids, cocaine etc. abuse lead to disinhibition and unprotected sex with multiple partners [21].

\section{CONCLUSION}

Axis I psychiatric morbidity was present significantly high in individuals with following risk factors-

1. History of multiple sex partners,

2. In the population who never used any barrier method during sexual activity and,

3. Those with history of sex with commercial sex workers.

Surprisingly the axis I psychiatric diagnosis was present significantly high in individuals aware about HIV and various routes of spread of HIV. So this study and the findings can help guiding the development of behavioural risk reduction and prevention programs in both the categories i.e. patients with psychiatric disorders and those infected with HIV. It can be recommended that all the HIV positive patients should be routinely screened for psychiatric disorders. Smaller sample size is the limitation of the study. Further studies with larger sample size can be helpful to confirm the findings.

\section{REFERENCES}


1. Stefan MD, Catalan J. Psychiatric patients and HIV infection: a new population at risk? Br J Psychiatry 1995;167:721-7.

2. Carey MP, Weinhardt LS, Carey KB. Prevalence of infection with HIV among the seriously mentally ill: Review of research and implications for practice. Professional Psychol Res Pract 1995;26(3):262-8.

3. Chandra PS, Ravi V, Puttaram S, Desai A. HIV and mental illness. Br J Psychiatry 1996;168:654-9.

4. Chandra PS, Krishna VAS, Ravi V, Desai A, Puttaram S. HIV related admissions in a psychiatric hospital: A five year profile. Indian J Psychiatry 1999;41:320-4.

5. Campos LN, Guimarães MD, Carmo RA, Melo AP, Oliveira HN, Elkington K McKinnon K. HIV, syphilis and hepatitis B and C prevalence among patients with mental illness: a review of the literature. Cad Saude Publica 2008;24(Suppl 4):S607-20.

6. Mini international neuropsychiatric interview (M.I.N.I.) English Version 6.0.0 ICD-10 USA: D. Sheehan, J. Janavs, R. Baker, K. Harnett-Sheehan, E. Knapp, M. Sheehan University of South Florida - Tampa. Available at http://www.nccpsychiatry.info/File/MINI600.pdf

7. Chandra PS, Carey MP, Carey KB, Shalinianant A, Thomas T. Sexual coercion and abuse among women with a severe mental illness in India: an exploratory investigation. Compr Psychiatry 2003;44: 205-12.

8. Guimaraes MD, McKinnon K, Campos LN, Melo AP, HIV risk behavioure of psychiatric patients with mental illness: a sample of Brazilian patients. Rev Bras Psiquiatr 2010;32 (4);351-60.

9. Moeller FG, Barratt ES, Dougherty DM, Schmitz JM, Swann AC. Psychiatric aspects of impulsivity. Am J Psychiatry 2001;158(11):1783-93.

10. Meade CS, Sikkema KJ. HIV risk behavior among adults with severe mental illness: a systematic review. Clin Psychol Rev 2005;25(4):433-57.

11. Devieux JG, Malow R, Lerner BG, Dyer JG, Baptista L, Lucenko B, Kalichman S. Triple jeopardy for HIV: substance using severely mentally ill adults. J Prev Interv Community Med 2007;3(1-2):5-18.

12. Kalichman SC, Kelly JA, Johnson JR, Bulto M. Factors associated with risk for HIV infection among chronic mentally ill adults. Am J Psychiatry 1994;151:221-7.

13. Carey KB, Weinhardt LS, Carey MP. Documented behavioral risk for human immunodeficiency virus (HIV) infection among seriously mentally ill out patients. Commun Mental Health J 1997;33:133-42.

14. Sacks M, Dermatis H, Looser-Ott S, Perry S. Seroprevalence of HIV and risk factors for AIDS in psychiatric inpatients. Hosp Coummun Psychiatry 1996;43:736-7.

15. Meyer-Bahlburg H, Nat R, Sugden R, Horwath E. Sexual activity and risk of HIV infection among patients with schizophrenia. Am J Psychiatry 1994;1(51):229-36.

16. Horwath E, Kramer M, Cournos F, Empfield M, Gewirtz G. Clinical presentations of AIDS and HIV infection in state psychiatric facilities. Psychiatr Serv 1989;40(5):502-6.

17. Cournos F, Empfield M, Horwath E, Schrage H. HIV infection in state hospitals: Case reports and long-term management strategies. Psychiatr Serv 1990;41(2):163-6.

18. Sacks MH, Silberstein C, Weiler P, Perry S. HIV-related risk factors in acute psychiatric inpatients. Psychiatr Serv 1990;41(4):449-51.

19. Saha MK, Chakrabarti S, Panda S, Chatterjee A, Sarkar S, Manna B. Prevalence of HCV \& HBV infection amongst HIV seropositive intravenous drug users and their non-injecting wives in Manipur, India. Indian J Med Res 2000;111:37-9.

20. Cournos F, McKinnon K. HIV seroprevalence among people with severe mental illness in the United States: a critical review. Clin Psychol Rev 1997;17(3):259-69.

21. St Lawrence JS, Jefferson KW, Alleyne E, Brasfield TL. Comparison of education versus behavioral skills training interventions in lowering sexual HIV-risk behavior of substance dependent adolescents. J Consult Clin Psychol 1995;63:154-7.

$$
\begin{aligned}
& \text { Acknowledgements - Nil; } \\
& \text { Source of Funding - Nil } \\
& \text { Conflict of Interest - Nil }
\end{aligned}
$$

